\title{
Human Biomonitoring of Engineered Nanoparticles: An Appraisal of Critical Issues and Potential Biomarkers
}

\author{
Enrico Bergamaschi \\ Laboratory of Industrial Toxicology, University of Parma Medical School, Via A. Gramsci 14, 43100 Parma, Italy \\ Correspondence should be addressed to Enrico Bergamaschi, enrico.bergamaschi@unipr.it
}

Received 5 January 2012; Revised 26 April 2012; Accepted 26 April 2012

Academic Editor: Ivo Iavicoli

Copyright (c) 2012 Enrico Bergamaschi. This is an open access article distributed under the Creative Commons Attribution License, which permits unrestricted use, distribution, and reproduction in any medium, provided the original work is properly cited.

The present paper deals with the applicability of biological monitoring to the assessment of exposure and possible effects deriving from exposure to engineered nanomaterials (NM). After establishing a conceptual framework in which human biomonitoring should be placed, the paper reviews the critical issues related to the unusual properties of NM affecting the implementation of biomonitoring activities for this new class of chemicals. Relying on the recent advances in the toxicogenomic, it is possible to assess whether specific biological pathways are activated or perturbed by specific NM. However, to evaluate if quantitative changes in these biomarkers can be used as indicators or predictors for toxicity in humans, validation on well characterised groups of exposed people is needed. At present, it appears more pragmatic to evolve NM-associated biomarker identification considering relevant biological responses found in environmental and occupational studies and assessing the early events associated with exposure to these NM. The battery of biochemical markers includes soluble molecules, antioxidant capacity, peroxidated lipids and carbonyl groups in serum proteins as a biomarkers of systemic inflammation and vascular adhesion molecules to assess endothelial activation/damage. Abnormalities in exhaled breath condensate chemistry reflecting intrinsic changes in the airway lining fluid and lung inflammation seem promising tools suitable for BM studies and are broadly discussed.

\section{Definition and Meaning of Human Biological Monitoring}

Biological monitoring (BM) has been defined in different ways, according to the purpose and the context [1-6]. In occupational health, BM deals with the systematic or repetitive measurement of chemical or biochemical markers in fluids, tissues, or other accessible samples from people exposed to or with past exposure to chemicals risk factors. The main objectives of such periodical measurements are (a) the assessment of individual or group exposure; (b) ensuring health protection by identifying early, specific nonadverse biological effect parameters which are indicative, if compared with adequate reference values, of an actual or potential condition leading to health damage; ultimately (c) the assessment of health risk to exposed subjects [2, 3]. BM can be used as a valid tool in the practice of occupational safety and health with the purpose of identifying potential hazards of new and emerging chemicals, including manufactured nanoparticles, and thus identifying groups at higher risk of health outcomes [2].
$\mathrm{BM}$ is becoming more popular as the number of biomarkers increases and the number of successful examples of field application proves the validity of such biomarkers. Biomarkers are regarded as early, preferably reversible, biological signs which are indicative, if compared with adequate reference values, of an actual or potential condition of exposure, effect, or susceptibility possibly resulting in health damage or disease [3]. Biomarkers are increasingly used as surrogate indicators of designated events in a biological system due to the inaccessibility of target organs; in spite of this limitation, it is thought that biomarkers are more directly related to the adverse effects which one attempts to prevent than any ambient measurement [4]. Depending on their toxicological significance, biomarkers have been classified in three main categories: biomarkers of exposure, biomarkers of effect, and biomarkers of susceptibility. A biomarker of exposure has been defined as "an exogenous substance or its metabolite or the product of an interaction between a xenobiotic agent and some target molecule or cell that is measured in a compartment within an organism" [5]. Providing objective demonstration of the absorption of 
chemicals in the body, exposure biomarkers can be useful in occupational toxicology for a more accurate risk assessment, reducing misclassification in epidemiological studies, and modelling internal dose.

A biomarker of effect is "any measurable biochemical, physiological or other alteration within an organism that, depending on magnitude, can be recognized as an established or potential health impairment or disease" [5]. Biomarkers of effect can be used in health surveillance programs aimed at the early diagnosis of exposure-related (or associated) diseases, but the application of effect monitoring is most often used to evaluate whether a well-characterized exposure is associated with a shift in the distribution of relevant biochemical or functional endpoints indicative of early changes in the target or critical organs/tissue. Biomarkers of susceptibility, including both inherent (e.g., genetic polymorphisms of toxicologically relevant phenotypes of drug metabolizing enzymes or DNA repair enzymes) and acquired conditions [5], should help to distinguish groups at risk at the same exposure levels, but they should be used as effect modifiers rather than as risk factors.

For preventive purpose, biomarkers should not be considered as diagnostic tests but rather as indicators reflecting early modifications preceding progressive structural or functional damage at the molecular, cellular, and tissue level, that is, changes possibly leading to adverse effects but completely reversible upon the removal from the exposure of concern. In order to be useful in risk assessment, a biomarker should provide relevant information on important issues concerning health risks and valid from both analytical and epidemiological aspects [6]. Validity relies on the intrinsic characteristics of the biomarker, due to its pathophysiological meaning, that is, the ability to reflect, even subtle, changes in a biological system; in particular, external validity is required to obtain results which can be generalized to other populations [2].

\section{Critical Issues of Biomonitoring for Engineered Nanomaterials}

The development of appropriate biomarkers requires the knowledge of pharmacokinetic and pharmacodynamic data for a given chemical, which are still lacking for many classes of NMs, in spite of the great development of in silico models [7]. The internal dose of a given chemical is usually assessed by both the amount of the chemical and/or its metabolites and the products of interaction with target biomolecules (DNA, proteins). For some metal nanoparticles, fullerenes and Single-Wall Carbon Nanotubes (SWCNTs), the available biokinetic data $[8,9]$ reveal appreciable translocation rates from the lung interstitium to bloodstream and secondary organ. Although such mechanisms can potentially explain the manifestations attributable to UFP exposure, at present, it is unknown whether it could represent a causal pathway for NM entailing nano-specific outcomes.

As compared to other chemical substances, NMs do not undergo biotransformation leading to moieties, or break, down by, products; on the other hand, the particle opsonisation by serum or membrane proteins, the specific proteins coating the nanoparticle surface ("corona" effect), is one of the key factors determining the fate and outcomes of nanomaterial interacting with biological systems $[10,11]$.

A specific type of interaction occurs when proteins adsorb, and this interaction affects both the particle and the protein function. For instance, $14 \mathrm{~nm}$ carbon black (CB) significantly adsorbs the cytokines IL-8 and TNF-alpha compared with a similar dose of $260 \mathrm{~nm} \mathrm{CB} \mathrm{[12].} \mathrm{TNF} \mathrm{alpha}$ bound to $14 \mathrm{~nm}$ CB induced a level of ICAM-1 expression that was no greater than the control level, suggesting that the TNF alpha activity may be inhibited.

Metal nanoparticles like cobalt [13], iron oxide [14] and zinc oxide, silver [15] can release metal ions, and the role of particle dissolution in biological media, as well as its prevention by doping particle surface, has paid attention for the clearance of the particle out of the deposition sites and for the effects of particles in target organs [8, 14, 16]. Agglomeration and solubility largely affect the biological behaviour of NMs and, ultimately, their organ distribution; low-soluble $\mathrm{CNT}$ or $\mathrm{TiO}_{2}$ nanoparticles show biopersistence, and their slow clearance lead to the tendency to accumulate over time with exposure $[8,9]$. Although some NMs have demonstrated to easily cross biological barriers, the magnitude of NMs into the systemic circulation could be negligible to lead significant internal dose. Analytical capabilities now permit quantization of "background levels" in people not knowingly exposed, but the toxicological significance of these low doses needs to be carefully assessed [17].

Data generated by toxicological tests can be used to establish a quantitative relationship between the different physico-chemical characteristics of nanoparticles and the response elicited [18]. For nanoparticles, controversies exist about the best descriptor of dose related with biological effects, particle number, and surface area being the best dose metrics for NMs both in vitro and in vivo. [19-21]. The unpredictable behaviour of several NMs would require to assess the dose-response relationship of the most sensitive body organ rather than solely on the organ through which nanoparticles enter the body. Although understanding target organ dose is still problematic, new methods for tracking and measuring NMs in vivo, currently applied to assess the effectiveness of dose delivered at target cells [22, 23], could provide effective tools for obtaining quantitative data that are essential for dosimetry model validation and, ultimately, for ascertaining the range of exposure level with no observed adverse effects (NOAELs).

\section{Identifying Relevant Effects and Mechanisms}

To develop biomarkers suitable for human studies involving people exposed to NMs, it has been suggested to use a stepwise approach to evolve nanoparticle-associated biomarker identification from biochemical, cellular, and animal studies, the same approach that has been used for studying air pollution-associated biomarkers [24]. Inhaled ultrafine particles (UFPs) and combustion-derived nanoparticles are 
capable of inducing oxidative stress in the lung as well as in systemic circulation and are involved in many adverse effects or pathological conditions associated with respiratory and cardiovascular disease outcomes. For environmental particles, oxidative stress and changes to biomolecules may arise from direct generation of reactive oxygen species from the surface, soluble compounds, such as, transition metals or organics, altered function of mitochondria or NADPHoxidase, and activation of inflammatory cells capable of generating ROS and reactive nitrogen species [25].

It should be emphasized that incidental UFPs, mostly generated by combustion sources, are heterogeneous in size and composition (including organics undergoing metabolic activation and producing reactive species, such as, polynuclear aromatic hydrocarbons, elemental carbon and metals), whereas NMs are intentionally made of defined composition and surface chemistry. Although similar in size, ambient and engineered nanoparticles may significantly differ for biological activity and toxicological properties. Since ambient UFPs are one of the components of a complex mixture of pollutants including oxidant gases and biocontaminants, it is difficult to attribute specific health outcomes to a specific class of contaminants.

Recent research has identified the most significant biological responses and target organ affected by different NM $[18,26-28]$ and the toxicity paradigms have been elucidated $[15,29,30]$.

Figure 1 summarizes some potential important factors in correlating exposure, dosimetry, and health effects of inhaled nanoparticles. Since nanoparticles have a greater potential to deposit and target both the upper and lower regions of the respiratory system and are capable to induce more oxidative stress and inflammation than their fine-sized counterparts, possibly leading to long-term effects, this justifies the study on their health impact [28].

Epidemiological studies have found hazardous respiratory effects from occupational exposure to some industrial processes involving generation of significant amounts of UFP, such as, carbon black [31], fumed silica [32], and metal oxide [33, 34]. However, also some few NMs, such as, titanium dioxide $\left(\mathrm{TiO}_{2}\right)$, copper oxide $(\mathrm{CuO}), \mathrm{ZnO}$ and iron oxide nanoparticles, cationic polystyrene, and C60 fullerene have demonstrated to have prooxidative and proinflammatory properties both in vitro and in vivo, mainly related to their surface reactivity and chemical composition [28], although not all NPs cause inflammation via a mechanism involving oxidative stress. Experimental studies have characterized tissue response to carbon nanotubes (CNTs) and showed that deposition following instillation or inhalation leads to transient inflammatory changes, lung tissue remodelling, and fibrosis $[35,36]$.

Since NMs can potentially affect multiple cellular functions and interfere with many components of the cell machinery [37], it is difficult to determine with conventional assay what are changes and adverse effects that may occur, and whether biochemical and/or functional changes can be material-specific or exposure-route specific. Conventional toxicology has used surrogate markers that are correlated with toxic responses to monitor adverse outcomes in inaccessible tissues. An alternative approach is suggested by system toxicology, which postulates that there are size-specific, shape-specific, and surface-specific effects and effectors for particles at the quantum range, which are different from the effects observed for microsized particulates [37-39].

The process of determining the relationship between a particular expression profile and the toxicological phenotype of the organism for a particular exposure or dose and at a particular time is called "phenotypic anchoring". This approach can be used in conjunction with lower doses of the toxicant to classify agents and to explore the mechanisms of toxicity, for example, by assessing transcriptional changes occurring after exposure to both low- and high-dose of $\mathrm{NMs}$, and detecting the biological responses by using transcriptome measurements. Toxicogenomics approach has been used in assessing specific mechanisms at the molecular level for silicon dioxide, dendrimers, and carbon nanoparticles, for example, SWCNT, Multi-Wall carbon Nanotubes (MWCNTs), carbon nanoonions and fullerenes, and metal nanoparticles (e.g., copper and silver), identifying patterns of cellular perturbations in specific pathways, through identification and quantification of global shifts in gene expression in cell models challenged with NMs [38-42].

SWCNT may induce cell apoptosis, which is characterized by upregulation expression of apoptosis-associated genes (e.g., p16, bax, hrk, bak1, p57, FGFR2, TGF beta receptor 1 and TNFAIP2 genes) and downregulation expression of cell-cycle-associated genes (such as cyclin D1, cdk2, cdk4, and $c d k 6$ ) as compared to normal cells [40]. Silica nanoparticles induced a higher level of acute phase proteins, such as, haptoglobin, C-reactive protein (CRP), and serum amyloid A (SAA) than larger silica particles (diameter $>100 \mathrm{~nm}$ ) after intravenously treatment; acute phase proteins, such as haptoglobin were significantly elevated in plasma of mice exposed to silica nanoparticles with a diameter of $70 \mathrm{~nm}$ (nSP70) compared to normal mice and those exposed to silica particles with a diameter of $1000 \mathrm{~nm}$. Furthermore, the CRP and SAA were also elevated in plasma of nSP70-treated mice. In addition, the level of these acute phase proteins was elevated in the plasma of mice after intranasal treatment with nSP30 [42].

Whole genome microarray analysis of the early gene expression changes induced by 10 and $500 \mathrm{~nm}$ amorphous silica nanoparticles showed that the magnitude of change for the majority of genes affected correlated more tightly with particle surface area than either particle mass or number, and gene expression changes were particle size specific [41]. However, the overall biological processes represented by all gene expression changes were nearly identical, irrespective of particle diameter, suggesting that on an equivalent nominal surface area basis, common biological modes of action are expected for nano- and supranano-sized silica particles. The most robust transcriptional change observed was an induction of the Cxcl2 chemokine (MIP-2a), also implicated in crystalline silica-induced lung neutrophil recruitment [41]. 


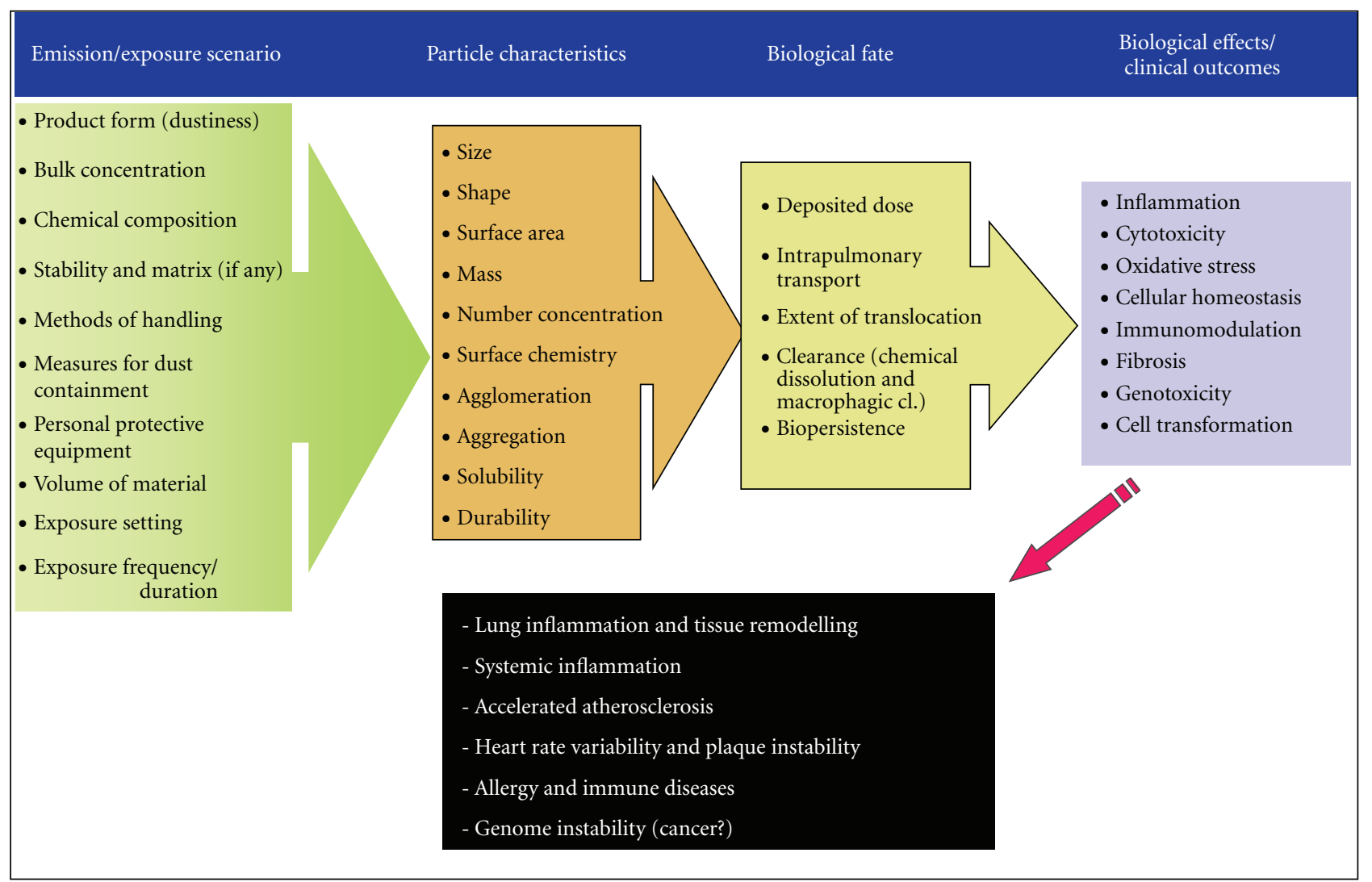

Figure 1: Potential important factors in correlating exposure, internal dose, and health effects of nanoparticles.

Pulmonary exposure to CNT resulted in an elevated series of measurable potential biomarkers in blood, including, genes expressed in the circulating blood cells and/or soluble proteins not unique to the type of particles [43]. In particular, MWCNT induced gene upregulation of more than half of the tested genes in the lung related to inflammation, oxidative stress, coagulation, and tissue remodelling and in a significant increase in the circulating blood gene expression of several biomarkers of neutrophil response. Interestingly, several genes were activated in the circulating blood cells but not in the lung at least at the $4 \mathrm{~h}$ after pulmonary exposure to MWCNT, for example, osteopontin, colony stimulating factor-1 (CSF-1), and insulin growth factor receptor $1(I G F-1 R)$. Pulmonary exposure to CNT also triggered the induction of primary cytokines, such as IL- 6 and IL- $1 \beta$, which regulate multiple pathways of the inflammatory cascade as well as secondary inflammatory mediators and chemokines which directly regulate leukocyte recruitment to the inflammatory site (32). Teeguarden et al. [44] identified a pattern of 109 proteins representing cellular processes affected by both SWCNT and crocidolite asbestos; in particular, one high-sensitivity marker of inflammation (S100a9) may represent a promising biomarker of human response to SWCNT exposure.

High-throughput toxicological studies thus support the existence of both nanoscale effects and specific molecular effectors differentiating nanotoxicology from conventional toxicology. Figure 2 summarizes such system-toxicologybased integrative approach to the identification of biomarkers. The perspective of identifing fingerprints of selected NMs by "-omic" techniques (i.e., metabolomic analysis, toxicogenomic, oxidative lipidomics based on mass spectrometry-based profiling of lipid profiles of exposed cells and tissues) applied to nanotoxicology will allow to assess whether particular biological pathways are activated or perturbed by specific nanoparticles and to evaluate if the quantitative changes in these biomarkers can be used as indicators or predictors for toxicity in humans.

\section{Biomarkers of Lung and Systemic Inflammation}

To assess the early events preceding progressive structural or functional damage at the molecular, cellular, and tissue level associated with exposure to NMs, the choice of potential biomarkers to be studied can include the changes that indicate local and systemic oxidative stress, systemic inflammation, and inflammatory response in target organs, such as, those in respiratory and cardiovascular systems. Although inflammatory pathways are the main mechanism investigated in relation to cardiovascular outcomes, other mechanisms triggered by UFPs exposure, such as, the involvement of vagal bronchopulmonary receptors and neuronal pathways initiated in the lung, should be considered [45]. 


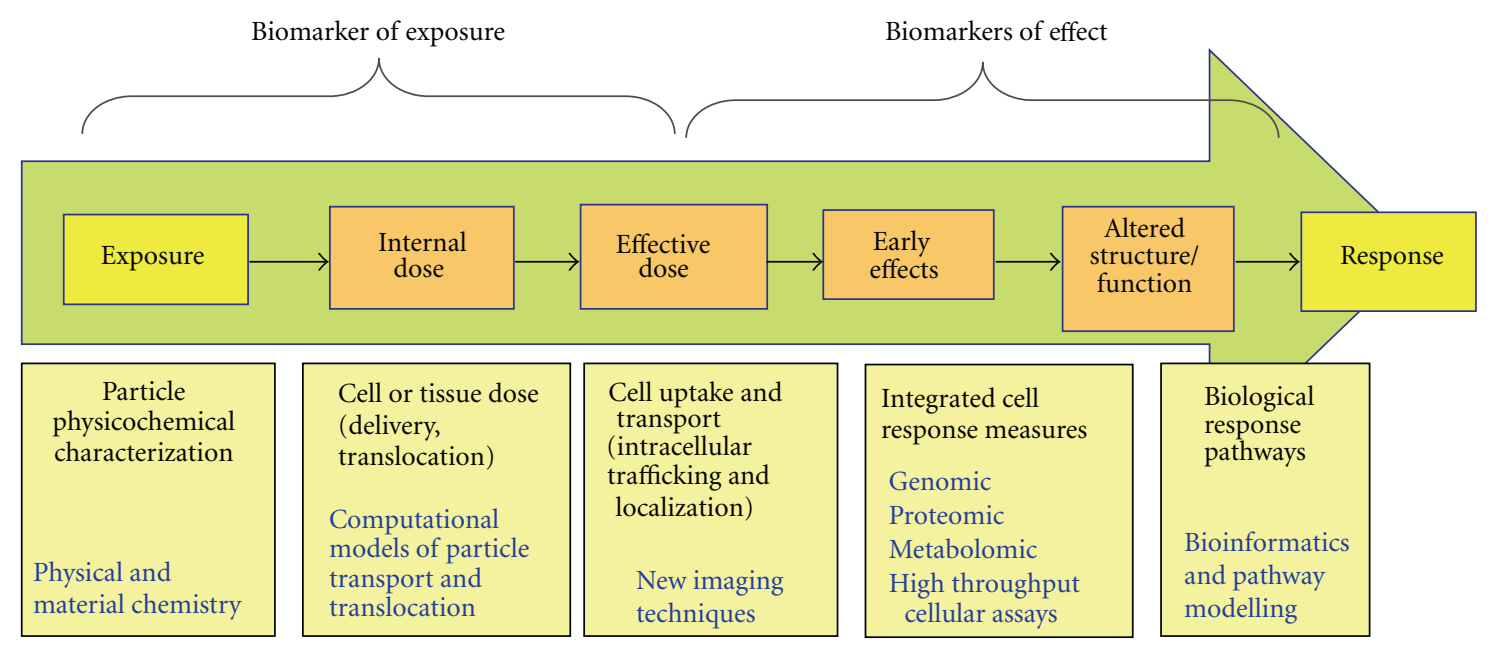

FIGURE 2: System toxicology-based integrative approach to the identification of biomarkers. Recent advances in “-omics" and new imaging techniques describing the cellular fate of NMs may lead to identify fingerprints of selected NMs, to assess whether particular biological pathways are activated or perturbed by NMs, and to evaluate if the quantitative changes in these biomarkers can be used as indicators or predictors for toxicity in humans.

Quantification of lung inflamma tion is currently based on invasive methods, including, the analysis of bronchoalveolar lavage fluid (BALF), bronchoscopy and bronchial biopsies, semi-invasive methods, such as, sputum induction, and the measurement of inflammatory biomarkers in plasma and urine which are likely to reflect systemic rather than lung inflammation [46]. Breath analysis has been suggested as a promising noninvasive approach that allows the identification of the inflammatory and oxidative stress biomarkers involved in the pathogenesis of various respiratory conditions both for clinical applications [46] and for investigating occupational lung diseases [47, 48].

Different biomarkers of effect, reflecting oxidative stress and inflammatory pathways, can be determined in EBC [46]; for instance, Thiobarbituric Acid Reactive Substances (TBARSs), such as, malondialdehyde, produced by lipoperoxidation of membranes, and 8-isoprostane, a peroxidation products of prostaglandin metabolism, can be quantified; changes in $\mathrm{pH}$, proteins, and proinflammatory cytokines, such as, leukotrienes $\mathrm{B}_{4}\left(\mathrm{LTB}_{4}\right)$ can also be determined as biomarkers of inflammation. Inflammatory response in the airways is characterized by an influx of neutrophils, whose activation is associated with a respiratory burst resulting in overproduction of hydrogen peroxide $\left(\mathrm{H}_{2} \mathrm{O}_{2}\right)$, which is measurable in EBC. Glutathione (GSH), which is present in high concentration in epithelial lining fluid and at tissue level of the lung, represents one of the major biological antioxidant defence mechanisms against reactive oxygen species and the secondary products ROS reacting with thiol groups can severely deplete the GSH pool.

Various classes of volatile organic compounds (VOCs) can also be measured in exhaled breath, including, the saturated hydrocarbons and oxygen-containing substances formed during the fatty acid lipid peroxidation of cell membranes [49].

A wide variety of carbonyl compounds are generated as secondary oxidation products during respiratory burst. In particular, saturated aldehydes, such as hexanal, heptanal, and nonanal are formed by the peroxidation of omega3 and -6 fatty acids (PUFAs), the basic components of cell membrane phospholipids. Volatile aldehydes are poorly soluble in blood and are therefore excreted into the breath within minutes of their formation in tissues, making it possible for the study of pulmonary diseases associated with inflammatory processes (e.g., COPD, asthma, interstitial lung disease) and the early diagnosis of lung cancer $[50,51]$.

Nitric Oxide (NO) is produced by all cellular components of pulmonary inflammation (macrophages, epithelial cells, mast cells, lymphocytes, and granulocytes). Studying $\mathrm{NO}$ exhaled from the lower airways offers a unique possibility to study features of pulmonary NO metabolism noninvasively in lung inflammatory states [52]. Under physiologic conditions, $\mathrm{NO}$ is unstable, reacting with oxygen to form oxides of nitrogen $\left(\mathrm{NO}_{x}\right)$, such as, nitrite $\left(\mathrm{NO}_{2}{ }^{-}\right)$ and nitrate $\left(\mathrm{NO}_{3}{ }^{-}\right)$and with superoxide anion to form the potent oxidant peroxynitrite $\left(\mathrm{ONOO}^{-}\right)$, which reacts with a wide variety of compounds, including, DNA, cellular lipids, and sulphydryl groups on proteins thus promoting nitrosative stress. Nitrosothiols (RS-NOs), which are formed by interaction of nitric oxide (NO) with GSH, can be reliably used as biomarkers in different inflammatory airway diseases [53]. Nitrite and nitrate in EBC have been used in evaluating the role of oxidative stress in acute responses to exposures that occur inside vehicles or during near-roadway activities [54].

A broad panel of circulating biomarkers reflecting inflammation endpoint, platelet activation, and antioxidant capacity by the copper-/zinc-superoxide dismutase $(\mathrm{Cu}$, $\mathrm{Zn}-\mathrm{SOD})$ and glutathione peroxidase-1 (GPx-1) activity has been investigated in studies on air pollution and health effects. Delfino et al. have assessed the relationship between exposure to particles of $0.25 \mu \mathrm{m}$ in aerodynamic diameter $\left(\mathrm{PM}_{0.25}\right)$, organic carbon, and elemental carbon from outdoor sources and changes in circulating biomarkers 
of systemic inflammation $[55,56]$. These studies showed the inactivation of antioxidant enzymes within erythrocytes by traffic-related pollutant components, including, polycyclic aromatic hydrocarbons, among a subgroup of people. Plasma interleukin-6 (IL-6) and soluble tumor necrosis factor-receptor II (sTNF-RII) were investigated during a longitudinal study considering both indoor and outdoor exposure and showed a positive association with vehicle emissions tracer. High-sensitivity C-reactive protein (hsCRP) in plasma, plasma fibrinogen, interleukin-6 (IL-6) could represent the best candidate for human BM following NM exposure.

Radomski et al. [57] showed that both urban dusts and engineered carbon particles, such as, CNT and carbon black, except $\mathrm{C}_{60} \mathrm{CS}$, stimulated platelet aggregation and accelerated the rate of vascular thrombosis in rat carotid arteries with a similar rank order of efficacy. All particles resulted in upregulation of GPIIb/IIIa in platelets. Similarly, exposure to nano- $\mathrm{Ag}(0.05-0.1 \mathrm{mg} / \mathrm{kg}$ i.v. or $5-10 \mathrm{mg} / \mathrm{kg}$ intratracheal instillation) in vivo enhanced platelet aggregation and promoted venous thrombus formation in rats [58]. Singlewalled carbon nanotubes $(0.01-1 \mathrm{mg} / \mathrm{kg})$ were injected into anesthetized mice, induced platelet activation in vitro, and exerted prothrombotic effects in the microcirculation in vivo, whereas similar dose of titanium dioxide $(1 \mathrm{mg} / \mathrm{kg})$ did not result in thrombus formation [59].

In order to assess early systemic prothrombotic effects induced by fine particle $(<2.5 \mu \mathrm{m})$ exposure, quantification of tissue factor (TF) activity in plasma, which is expressed in subendothelial cells upon injury or on the surface of circulating monocytes, macrophages and neutrophils, and the levels of plasminogen activator inhibitor-1 (PAI-1), can also be proposed as biomarkers [60].

The endothelium plays an important role in maintaining the vascular homeostasis by producing vasoactive factors that regulate the tone of the vascular system in response to cell surface receptor stimulation or mechanical stress but also in the regulation of vascular inflammation and thrombosis. NMs can directly affect endothelial cells metabolism via oxidative stress generation and endothelial repair capacity $[61,62]$. For instance, exposure to ultrafine $\mathrm{TiO}_{2}$ particles can affect vasomotor function with minimal pulmonary effects [63]. Vesterdal et al. [64] showed that exposure of young and aged apolipoprotein $\mathrm{E}$ knockout mice $\left(\mathrm{apoE}^{-/-}\right)$ to $\mathrm{CB}$ (Printex 90, $14 \mathrm{~nm}$ average size) by intratracheal instillation, resulted in modest vasomotor impairment, with a lack in association with nitrosative stress (3-nitrotyrosine) and without increases in the expression of vascular adhesion molecule (VCAM-1) and intercellular adhesion molecule (ICAM-1) on endothelial cells or in plaque progression.

\section{Biomarkers of Oxidative Stress and DNA Damage}

Panel studies and cross-sectional investigations on health effects of particulate matter exposure have found consistent associations between exposure to combustion-derived particles and products of oxidative damage of DNA and lipids
[65-67]. Among the DNA oxidation products, such as 8oxo-7,8-dihydroguanine (8-oxoGua) or the corresponding deoxynucleoside 8-oxo-7,8-dihydro-2' -deoxyguanosine (8oxodG) measured in DNA and urine, the exocyclic M1 adduct to guanine (M1dG) was the most studied. Among the biomarkers of lipid peroxidation products measured in EBC, blood, or urine, both conjugated dienes (CDs), lipid hydroperoxides, malondialdehyde (MDA), Thiobarbituric Acid Reactive Substances (TBARSs), and F2-isoprostanes have been assessed. Base excision repair of oxidative damage to DNA measured in urine, such as, 8-hydroxy-2'deoxyguanosine (8OHdG), seems to originate mostly from the oxidation of the deoxynucleotide pool and does not represent solely repairing/excretion of the oxidized DNA guanine. Once produced, $8 \mathrm{OHdG}$ is very stable and is not further metabolized in the systemic circulation. After exposure to oxidants, the repair and final $8 \mathrm{OHdG}$ excretion in urine is rapid, that is, within at least 24 hours [68]. Increased $8 \mathrm{OHdG}$ urinary levels within each shift and between days have been shown in workers exposed to low levels of respirable $\mathrm{PM}_{4}$ (range 25-71 $\mu \mathrm{g} / \mathrm{m}^{3}$ ) [69].

Whereas the DNA damaging potential of many nanoparticles is known, in vitro studies have demonstrated that NMs of different composition (metal/metal-oxide nanoparticles, silica, quantum dots, fullerenes, nanofibers) can alter DNA structure by oxidative mechanisms but can also interfere by mechanical hindrance with cellular and nuclear components, like, microtubules of the mitotic spindle [70,71].

The majority of the NM tested both in vitro and in vivo, such as, metal nanoparticles $[13,72,73]$ and both SWand MWCNT [36, 74, 75] are able to cause DNA strand breaks or oxidative DNA lesions. Chromosome breakage and chromosome loss, the main genotoxicity endpoints, can be detected and quantified in target cells using the cytokinesisblock micronucleus method (CBMN assay), originated from acentric chromosome fragments or whole chromosomes lagging behind during cell division, coupled with the fluorescence in situ hybridization (FISH) analysis. DNA damage in peripheral blood leukocytes can be quantified by single cell gel electrophoresis (SCGE; Comet assay) a simple and sensitive method for detecting DNA strand breaks and alkali-labile sites, while oxidatively damaged DNA can be analyzed using the enzyme formamidopyrimidine glycosylase (FPG) and endonuclease III (endo III) which detect, respectively, oxidized purines and pyrimidines [75]. Although interactions between the particles and the assay cannot be totally excluded, the use of Comet assay in humanbiomonitoring studies could provide valuable information for hazard identification of NMs [76]. Some studies showed dose-effect and dose-response relationships between the mass concentration of NM and the frequency of micronucleated lymphocytes, with a threshold for the above effects $[72,75]$.

DNA methylation, a major genomic mechanism of gene expression control, can be affected by reactive oxygen species (ROS), which are considered one of the main cellular stressors generated by PM exposure [77] as well as by some metals [78]. Conditions associated with reduced global DNA methylation content have been shown to interact with ambient PM 
exposure to produce health-related outcomes. For instance, gene expression and the associated epigenetic changes have been demonstrated following exposure to metal-rich PM with aerodynamic diameters $<10 \mu \mathrm{m}\left(\mathrm{PM}_{10}\right)$ in workers in an electric furnace [79].

MicroRNAs (miRNAs) are highly conserved, noncoding small RNAs that regulate the expression of broad gene networks at the posttranscriptional level [80] demonstrating that gold nanoparticles (AuNPs) altered the expression of 19 genes in human fetal lung fibroblasts, upregulating the microRNA-155 (miR-155), and downregulating the PROS1 gene. Silencing of miR-155 established PROS1 as its possible target gene. DNA methylation profiling analysis of the PROS1 gene revealed no changes in the methylation status of this gene in AuNP-treated fibroblasts, whereas chromatin condensation and reorganization were observed in the nucleus of fibroblasts exposed to AuNPs. These findings provide further insights into the molecular mechanisms underlying toxicity of AuNPs and their impact on epigenetic processes.

\section{Biomarkers of Neurotoxicity}

Existing research has shown that several NMs, like, quantum dots [81] and SWCNT [82] are capable of crossing the bloodbrain barrier (BBB), damage it, and enter the brain. $\mathrm{TiO}_{2}$ [83] and manganese oxide nanoparticles were capable of translocating along the olfactory nerve pathway to the brain after intranasal instillation exposure, accumulating in the olfactory bulb, cortex, and cerebellum [84]. The deposition in the brain of NMs such as, ferrous oxide [85] and CB [86] can stimulate oxidative stress, inflammatory responses, and pathological changes. The mechanisms of neuron injury are diverse for a wide variety of materials used and NMs produce different effects from environmental particles with potential effects both on peripheral and central nervous systems [87]. Adsorption and inhibition of acetylcholinesterase, a key enzyme present in the brain, blood, and nervous system, by $\mathrm{SiO}_{2}, \mathrm{TiO}_{2}, \mathrm{Al}_{2} \mathrm{O}_{3}, \mathrm{Al}, \mathrm{Cu}$, carbon-coated copper, SWCNT and MWCNT suggest an interference of NMs with neurochemical processes and a use of $\mathrm{AChE}$ as a potential biomarker of neurotoxicity [88]. Dopaminergic neurons can be specifically targeted in vitro by a broad spectrum of NM, including $\mathrm{Mn}, \mathrm{Ag}$, or $\mathrm{Cu}$ nanoparticles [89]. In vivo studies showed $\mathrm{SiO}_{2}$-NPs entered into the brain and especially deposited in the striatum and induced oxidative damage and inflammation in dopaminergic brain areas with subsequent depletion of neuromediators [90].

Aerosolized welding fumes generated from two different welding processes, gas metal arc-mild steel (GMA-MS; low Mn, less water soluble), and manual metal arc-hard surfacing (MMA-HS; high Mn, more water-soluble) welding caused persistent molecular alterations in dopaminergic targets of treated animals [91]. To assess early effects from chemicals targeting the dopaminergic systems a neurochemical and neuroendocrine approach based on surrogate biomarkers in peripheral media has been previously developed [92]. Neurotoxicity of Mn to dopaminergic systems, investigated in male workers occupationally exposed to Mn oxides containing fumes and metallurgic dusts, was revealed by increase in serum PRL levels [93].

It is unlikely that acute high dose causes CNS effects occur, whereas the long-term accumulation of low doses of ENP cannot be excluded; thus, the possibility that chronic exposures to NM can influence brain neurochemistry triggering or aggravating pathological processes cannot be ruled out [94].

\section{Development of Biomarkers for Human Studies and Health Impact Assessment}

The health effects of nanoparticles are, to a large extent, unknown, and currently there is no report of any definitive human disease that is caused by NMs exposure. Specific health end points on which future human studies should be focused are a controversial issue; as a result, studies on chronic effects with adequate latency are probably not feasible in the near future. In contrast, initial epidemiological studies (e.g., based on a cross-sectional design) could benefit of biomarkers to detect possible effects.

Therefore, there is a need for the selection of candidate biomarkers of early effects to be used in human studies.

The literature on short-term effect of air pollutants and the available literature on NMs suggests identifying multiple biomarkers, a biomarker profile, to assess both effects at the "portal of entry" (e.g., inflammatory changes, short-term respiratory changes, respiratory, eye or skin irritation) and systemic effects (e.g., heart-rate variability, platelet aggregation and prothrombotic changes, acute phase proteins) [95]. Biochemical tests or functional parameters to be assessed should be supported by consistent pathophysiological mechanisms, considering that the health end points ascribed to UFP, and possibly to NM, (cardiovascular, pulmonary, inflammatory) are often unspecific, show high prevalence in the general population, and share multiple nonoccupational risk factors [96].

Table 1 summarizes a panel of biomarkers of exposure and effect potentially available for human biomonitoring studies aimed at assessing early (i.e., subclinical) effects and health outcomes forerunners of disease endpoints. In bold are listed the more promising biomarkers (e.g., validated in human studies on people exposed to different ultrafine or fine particulates or fractions of them).

Since "nano-specific" biomarkers (or "nano-specific" effects) are difficult to demonstrate, practical considerations suggest to focus on the sensitivity instead of the specificity of biomarkers, to assess the causality of exposure conditions/scenarios and association with hazards (e.g., at workplace) but also to identify and validate, among a panel of already available biomarkers, the most suitable for BM studies in people exposed to NMs [97]. In spite of the advances made to ensure a higher degree of workers protection, epidemiological data specifically derived from nanoparticleexposed humans, which should allow to validate biomarkers, are currently not available, owing to a number of issues, including the short latency since the introduction of $\mathrm{NM}$ 
TABLE 1: Biomarkers of exposure and effect potentially available for human biomonitoring studies assessing exposure-effect relationships between particulate matter/ultrafine particles and health effects. In bold are listed the more promising biomarkers (e.g., validated in human studies on people exposed to different ultrafine or fine particulates or known fractions), whereas in italic are reported some potential biomarkers. Legend: EBC: Exhaled Breath Condensate; MDA: Malondialdehyde; T-BARS: Thiobarbituric Acid Reactive Substances; LTB 4 : Leucotriene-B ; $_{4}$ NO: Nitric Oxide; 8-OH-dG: 8-hydroxy-2'-deoxyguanosine; 8-oxo-Gua: 8-oxo-7,8-dihydroguanine; 4-HNE: 4-hydroxy-2nonenal; CC16: Clara Cell protein; hsCRP: high sensitivity C-reactive protein; IL-6: plasma Interleukin 6; sTNF-RII: soluble Tumor Necrosis Factor-receptor II; PAI-1: plasminogen activator inhibitor-1; V-CAM: vascular adhesion molecule; FPG-ENDOIII: lesions detected as sites in DNA sensitive to formamidopyrimidine DNA glycosylase and endonuclease III.

\begin{tabular}{|c|c|c|}
\hline Exposure & Effective dose/early effect & Altered structure/function \\
\hline $\begin{array}{l}\text { (ii) Circulating particles } \\
\text { (iii) Particle uptake by specialized cells (e.g., } \\
\text { macrophages) } \\
\text { (iv) Elemental analysis (for metallic NM, e.g., } \\
\text { metal oxides) in biological fluids } \\
\text { (v) Protein modification ("corona") }\end{array}$ & $\begin{array}{l}\text { (i) Lipid peroxidation products in EBC or } \\
\text { blood (MDA, T-BARS, conjugated dienes, } \\
\text { LTB }_{4} \text {, F2- and 8-isoprostane) } \\
\text { (ii) Oxidatively damaged DNA (8-OH-dG, 8- } \\
\text { oxo-Gua) } \\
\text { (iii) Exhaled NO and nitrosative stress products } \\
\text { (3-nitrotyrosine) } \\
\text { (iv) Carbonyl compounds (4-HNE) in EBC } \\
\text { (v) Serum pneumoproteins (CC16) } \\
\text { (vi) Platelet activation/aggregation and pro- } \\
\text { thrombotic changes } \\
\text { (vii) Acute phase proteins (hsCRP), IL-6, and } \\
\text { sTNF-RII } \\
\text { (viii) Clotting factors (fibrinogen, PAI-1), } \\
\text { blood microparticles } \\
\text { (ix) Tissue factor (TF) activity in plasma } \\
\text { (x) Vascular adhesion molecules (V-CAM-1) } \\
\text { (xi) Upregulation of GPIIb/IIIa in platelets }\end{array}$ & $\begin{array}{l}\text { (iii) Micronucleus } \\
\text { (iv) DNA strand breaks (Comet } \\
\text { assay + FPG-ENDO III) } \\
\text { (v) DNA hypomethylation } \\
\text { (vi) MicroRNAs (miRNAs) }\end{array}$ \\
\hline
\end{tabular}

on the market, the overlap in exposure to combustionderived UFP and engineered nanoparticles, the lack of standardized exposure metrics, the difficulty in identifying a target population with long, and consistent exposure leading to appreciable health effects [98].

In epidemiological research, BM is aimed at overcoming the growing frustration with the limitations of such crude markers of exposure as job titles, exposure registries or point estimates of airborne pollution. We should instead assess whether exposure to different NMs may lead to the same pathway for disease or share common mechanisms. But, to avoid "epidemiological frustrations" it is mandatory to identify at least intermediate biological changes of "acute" or "short-term" effects that could be indicative, if not predictive, of disease and apply them in cross-sectional investigations combining both exposure characterization to a given NM and sufficiently validated biomarkers.

For the NMs with known mechanisms or that share similar injury mechanisms (i.e., oxidative stress and inflammation, DNA damage) with UFPs, it is theoretically feasible to conduct biomarker studies starting with similar approaches; for example, to assess the early events associated with exposure to these NPs, biochemical changes indicative of local and systemic oxidative stress, systemic inflammation, and inflammatory response in target organs can be used [99]. Inflammatory biomarkers could be monitored in workers by using noninvasive methods (e.g., EBC collection). Pneumoproteins such as Clara cell protein (CC16) and surfactantassociated protein B (SP-B) in the serum have been validated as markers of alveolocapillary barrier integrity/permeability in human studies on gaseous/particulate pollutants [100, 101]. Recently, CC16 determination in serum was studied in workers occupationally exposed to NM [102]. Besides CC16, the high-sensitivitiy Reactive C protein levels and inflammatory cell activation (increased ICAM-1 in macrophages) showed statistically significant changes among NM workers.

To date, exposure assessment and characterization represent the main issues in risk assessment; provided that exposure is, quantitatively or qualitatively, documented, then BM studies could be consistently implemented. Metal NPs which release metal ions or dissolve in biological media may be detectable (as metal species, not as particles) with appropriate analytical methods.

To give an estimate of deposited dose of particles by noninvasive techniques, Goldoni et al. [103] have developed a portable device designed to monitor the on-line exhalation kinetics of particles in a single breath and validated it in field studies of workers occupationally exposed to cristobalite in the size range of $0.3-2.5 \mu \mathrm{m}$ [103] and to welding fumes [104]. Although the advantages of such an approach need further validation with different aerosols and model nanoparticles, the method suggests a tool to assess the dose of particles deposited within the respiratory tract.

By the breath analysis, tissue dose of pneumotoxic metals has been assessed in both workers occupationally exposed to hard metals (Co, Ti) [105], chromium(VI) [106]. Whether this technique is applicable to quantify the dose of metals eventually released by NMs deposited in the airways should be further assessed in field studies. 
Although we are not able, at present, to identify "nanospecific" biomarkers that meet all the above criteria, we can use a battery of available biomarkers of local and systemic inflammation and oxidative stress to identify hazards and groups at risk. Certainly, it will take years to develop a panel of biomarkers suitable as indicators of exposure-specific disease outcomes, but relying on our knowledge from the air pollution studies, occupational exposures to particles and fibres of concerns, and advances in "-omics" techniques applied to nanotoxicology we can identify early biological responses related to injury pathways upon exposure to NMs.

Practical issues, including, cost, exposure levels (which are able to lead to "effective dose"), analytical requirements, and selection of an adequate sampling strategy, should be considered in every study. Biological materials should certainly be easy to obtain in sufficient amounts under routine conditions and without unacceptable discomfort and health risk for the individual or worker.

Evaluation of the possible health effects from exposure to NMs requires a stepwise approach considering the knowledge of the likelihood of a known exposure, tracking changes of such characterized exposure over time by exposure registries, conducting targeted epidemiological investigations, and possibly applying selected biomarkers [2, 24, 107, 108].

There are many efforts at international level to identify companies manufacturing NM and workers likely to be exposed to NMs, and some studies on occupational cohorts have been put in place [108-110]. The heterogeneity of NMs, making difficult to identify and recruit enough workers with the same exposure pattern, could be addressed by the use of biomarkers [98].

The feasibility of BM studies in NM workers should consider both conceptual and practical issues, such as: (i) data on the temporal trends in exposure levels; (ii) identification of parameters able to reflect internal exposure or early/reversible biological changes; (iii) specific analytical methods kept under control by quality assurance; (iv) establishing reference ranges and limit values which enable the interpretation of eventual changes; (v) assessment of the health significance and predictive value of observed changes.

\section{Acknowledgment}

This work supported by the EU-funded research project "Safe Nano Worker Exposure Scenarios"-SANOWORK (Grant no. N.FP7-280716).

\section{References}

[1] R. L. Zielhuis and T. P. Henderson, "Definitions of monitoring activities and their relevance for the practice of occupational health," International Archives of Occupational and Environmental Health, vol. 57, no. 4, pp. 249-257, 1986.

[2] P. A. Schulte and J. E. Hauser, "The use of biomarkers in occupational health research, practice, and policy," Toxicology Letters. In press.

[3] M. Manno, C. Viau, J. Cocker et al., "Biomonitoring for occupational health risk assessment (BOHRA)," Toxicology Letters, vol. 192, no. 1, pp. 3-16, 2010.
[4] R. R. Lauwerys and P. Hoet, Industrial Chemical Exposure. Guidelines for Biological Monitoring, vol. 1, Lewis Publishers, Boca Raton, Fla, USA, 2nd edition, 1993.

[5] NRC, "National Research Council, Biological markers in environmental health research," Environmental Health Perspective, vol. 74, pp. 3-9, 1987.

[6] R. Smolders, A. Bartonova, P. J. Boogaard et al., "The use of biomarkers for risk assessment: reporting from the INTARESE/ENVIRISK Workshop in Prague," International Journal of Hygiene and Environmental Health, vol. 213, no. 5, pp. 395-400, 2010.

[7] J. E. Riviere and C. L. Tran, "Pharmacokinetics of nanomaterials," in Nanotoxicology: Characterization, Dosing and Health Effects, pp. 127-140, Informa Healthcare, New York, NY, USA, 2007.

[8] M. Geiser and W. G. Kreyling, "Deposition and biokinetics of inhaled nanoparticles," Particle and Fibre Toxicology, vol. 7, article 2, 2010.

[9] S. T. Holgate, "Exposure, uptake, distribution and toxicity of nanomaterials in humans," Journal of Biomedical Nanotechnology, vol. 6, no. 1, pp. 1-19, 2010.

[10] M. Lundqvist, J. Stigler, G. Elia, I. Lynch, T. Cedervall, and K. A. Dawson, "Nanoparticle size and surface properties determine the protein corona with possible implications for biological impacts," Proceedings of the National Academy of Sciences of the United States of America, vol. 105, no. 38, pp. 14265-14270, 2008.

[11] M. Lundqvist, J. Stigler, T. Cedervall et al., "The evolution of the protein corona around nanoparticles: a test study," ACS Nano, vol. 5, no. 9, pp. 7503-7509, 2011.

[12] D. M. Brown, C. Dickson, P. Duncan, F. Al-Attili, and V. Stone, "Interaction between nanoparticles and cytokine proteins: impact on protein and particle functionality," Nanotechnology, vol. 21, no. 21, Article ID 215104, 2010.

[13] R. Colognato, A. Bonelli, J. Ponti et al., "Comparative genotoxicity of cobalt nanoparticles and ions on human peripheral leukocytes in vitro," Mutagenesis, vol. 23, no. 5, pp. 377-382, 2008.

[14] J. M. Pettibone, A. Adamcakova-Dodd, P. S. Thorne, P. T. O'Shaughnessy, J. A. Weydert, and V. H. Grassian, "Inflammatory response of mice following inhalation exposure to iron and copper nanoparticles," Nanotoxicology, vol. 2, no. 4, pp. 189-204, 2008.

[15] H. J. Johnston, G. Hutchison, F. M. Christensen, S. Peters, S. Hankin, and V. Stone, "A review of the in vivo and in vitro toxicity of silver and gold particulates: particle attributes and biological mechanisms responsible for the observed toxicity," Critical Reviews in Toxicology, vol. 40, no. 4, pp. 328-346, 2010.

[16] P. Borm, F. C. Klaessig, T. D. Landry et al., "Research strategies for safety evaluation of nanomaterials, Part V: role of dissolution in biological fate and effects of nanoscale particles," Toxicological Sciences, vol. 90, no. 1, pp. 23-32, 2006.

[17] I. Iavicoli, E. J. Calabrese, and M. A. Nascarella, "Exposure to nanoparticles and hormesis," Dose-Response, vol. 8, no. 4, pp. 501-517, 2010.

[18] K. Aschberger, H. J. Johnston, V. Stone et al., "Review of carbon nanotubes toxicity and exposure-appraisal of human health risk assessment based on open literature," Critical Reviews in Toxicology, vol. 40, no. 9, pp. 759-790, 2010.

[19] K. Wittmaack, "In search of the most relevant parameter for quantifying lung inflammatory response to nanoparticle 
exposure: particle number, surface area, or what?" Environmental Health Perspectives, vol. 115, no. 2, pp. 187-194, 2007.

[20] E. Kuempel, C. Tran, V. Castranova, and A. Bailer, "Lung dosimetry and risk assessment of nanoparticles: evaluating and extending current models in rats and humans," Inhalation Toxicology, vol. 18, no. 10, pp. 717-724, 2006.

[21] O. Schmid, W. Möller, M. Semmler-Behnke et al., "Dosimetry and toxicology of inhaled ultrafine particles," Biomarkers, vol. 14, supplement 1, pp. 67-73, 2009.

[22] F. Tian, A. Prina-Mello, G. Estrada et al., "A novel assay for the quantification of internalized nanoparticles in macrophages," Nanotoxicology, vol. 2, no. 4, pp. 232-242, 2008.

[23] H. H. Chen, C. C. Chien, C. Petibois et al., "Quantitative analysis of nanoparticle internalization in mammalian cells by high resolution X-ray microscopy," Journal of Nanobiotechnology, vol. 9, article 14, 2011.

[24] N. Li and A. E. Nel, "Feasibility of biomarker studies for engineered nanoparticles: what can be learned from air pollution research," Journal of Occupational and Environmental Medicine, vol. 53, no. 6, pp. S74-S79, 2011.

[25] P. Møller, N. R. Jacobsen, J. K. Folkmann et al., "Role of oxidative damage in toxicity of particulate," Free Radical Research, vol. 44, no. 1, pp. 1-46, 2010.

[26] A. Helland, P. Wick, A. Koehler, K. Schmid, and C. Som, "Reviewing the environmental and human health knowledge base of carbon nanotubes," Environmental Health Perspectives, vol. 115, no. 8, pp. 1125-1131, 2007.

[27] T. Pappi, D. Schiffmann, D. Weiss, V. Castranova, V. Vallyathan, and Q. Rahman, "Human health implications of nanomaterial exposure," Nanotoxicology, vol. 2, no. 1, pp. 927, 2008.

[28] A. K. Madl and K. E. Pinkerton, "Health effects of inhaled engineered and incidental nanoparticles Health effects of inhaled nanoparticles," Critical Reviews in Toxicology, vol. 39, no. 8, pp. 629-658, 2009.

[29] A. Nel, T. Xia, L. Mädler, and N. Li, "Toxic potential of materials at the nanolevel," Science, vol. 311, no. 5761, pp. 622-627, 2006.

[30] J. Muller, F. Huaux, A. Fonseca et al., "Structural defects play a major role in the acute lung toxicity of multiwall carbon nanotubes: toxicological aspects," Chemical Research in Toxicology, vol. 21, no. 9, pp. 1698-1705, 2008.

[31] J. Wellmann, S. K. Weiland, G. Neiteler, G. Klein, and K. Straif, "Cancer mortality in German carbon black workers 1976-98," Occupational and Environmental Medicine, vol. 63, no. 8, pp. 513-521, 2006.

[32] R. Merget, T. Bauer, H. Küpper et al., "Health hazards due to the inhalation of amorphous silica," Archives of Toxicology, vol. 75, no. 11, pp. 625-634, 2002.

[33] J. M. Antonini, "Health effects of welding," Critical Reviews in Toxicology, vol. 33, no. 1, pp. 61-103, 2003.

[34] J. C. J. Luo, K. H. Hsu, and W. S. Shen, "Inflammatory responses and oxidative stress from metal fume exposure in automobile welders," Journal of Occupational and Environmental Medicine, vol. 51, no. 1, pp. 95-103, 2009.

[35] J. Muller, F. Huaux, N. Moreau et al., "Respiratory toxicity of multi-wall carbon nanotubes," Toxicology and Applied Pharmacology, vol. 207, no. 3, pp. 221-231, 2005.

[36] A. A. Shvedova, E. Kisin, A. R. Murray et al., "Inhalation vs. aspiration of single-walled carbon nanotubes in C57BL/6 mice: inflammation, fibrosis, oxidative stress, and mutagenesis," American Journal of Physiology, vol. 295, no. 4, pp. L552L565, 2008.

[37] A. A. Shvedova, V. E. Kagan, and B. Fadeel, "Close encounters of the small kind: adverse effects of man-made materials interfacing with the nano-cosmos of biological systems," Annual Review of Pharmacology and Toxicology, vol. 50, pp. 63-88, 2010.

[38] A. Poma and M. L. Di Giorgio, “Toxicogenomics to improve comprehension of the mechanisms underlying responses of in vitro and in vivo systems to nanomaterials: a review," Current Genomics, vol. 9, no. 8, pp. 571-585, 2008.

[39] B. Yang, Q. Wang, R. Lei et al., "Systems toxicology used in nanotoxicology: mechanistic insights into the hepatotoxicity of nano-copper particles from toxicogenomics," Journal of Nanoscience and Nanotechnology, vol. 10, no. 12, pp. 85278537, 2010.

[40] D. Cui, F. Tian, C. S. Ozkan, M. Wang, and H. Gao, "Effect of single wall carbon nanotubes on human HEK293 cells," Toxicology Letters, vol. 155, no. 1, pp. 73-85, 2005.

[41] K. M. Waters, L. M. Masiello, R. C. Zangar et al., "Macrophage responses to silica nanoparticles are highly conserved across particle sizes," Toxicological Sciences, vol. 107, no. 2, pp. 553-569, 2009.

[42] K. Higashisaka, Y. Yoshioka, K. Yamashita et al., "Acute phase proteins as biomarkers for predicting the exposure and toxicity of nanomaterials," Biomaterials, vol. 32, no. 1, pp. 39, 2011.

[43] A. Erdely, T. Hulderman, R. Salmen et al., "Cross-talk between lung and systemic circulation during carbon nanotube respiratory exposure. Potential biomarkers," Nano Letters, vol. 9, no. 1, pp. 36-43, 2009.

[44] J. G. Teeguarden, B. J. Webb-Robertson, K. M. Waters et al., "Comparative proteomics and pulmonary toxicity of instilled single-walled carbon nanotubes, crocidolite asbestos, and ultrafine carbon black in mice," Toxicological Sciences, vol. 120, no. 1, pp. 123-135, 2011.

[45] M. Lotti, I. Olivato, and L. Bergamo, "Inflammation and short-term cardiopulmonary effects of particulate matter," Nanotoxicology, vol. 3, no. 1, pp. 27-32, 2009.

[46] P. Montuschi, "Analysis of exhaled breath condensate in respiratory medicine: methodological aspects and potential clinical applications," Therapeutic Advances in Respiratory Disease, vol. 1, no. 1, pp. 5-23, 2007.

[47] M. Corradi, P. Gergelova, and A. Mutti, "Use of exhaled breath condensate to investigate occupational lung diseases," Current Opinion in Allergy and Clinical Immunology, vol. 10, no. 2, pp. 93-98, 2010.

[48] M. Gube, J. Ebel, P. Brand et al., "Biological effect markers in exhaled breath condensate and biomonitoring in welders: impact of smoking and protection equipment," International Archives of Occupational and Environmental Health, vol. 83, no. 7, pp. 803-811, 2010.

[49] D. Poli, P. Carbognani, M. Corradi et al., "Exhaled volatile organic compounds in patients with non-small cell lung cancer: cross sectional and nested short-term follow-up study," Respiratory Research, vol. 6, article 71, 2005.

[50] M. Corradi, I. Rubinstein, R. Andreoli et al., "Aldehydes in exhaled breath condensate of patients with chronic obstructive pulmonary disease," American Journal of Respiratory and Critical Care Medicine, vol. 167, no. 10, pp. 1380-1386, 2003.

[51] D. Poli, M. Goldoni, M. Corradi et al., "Determination of aldehydes in exhaled breath of patients with lung cancer by 
means of on-fiber-derivatisation SPME-GC/MS," Journal of Chromatography B, vol. 878, no. 27, pp. 2643-2651, 2010.

[52] P. Pacher, J. S. Beckman, and L. Liaudet, "Nitric oxide and peroxynitrite in health and disease," Physiological Reviews, vol. 87, no. 1, pp. 315-424, 2007.

[53] M. Corradi, P. Montuschi, L. E. Donnelly, A. Pesci, S. A. Kharitonov, and P. J. Barnes, "Increased nitrosothiols in exhaled breath condensate in inflammatory airway diseases," American Journal of Respiratory and Critical Care Medicine, vol. 163, no. 4, pp. 854-858, 2001.

[54] R. J. Laumbach and H. M. Kipen, "Acute effects of motor vehicle traffic-related air pollution exposures on measures of oxidative stress in human airways," Annals of the New York Academy of Sciences, vol. 1203, pp. 107-112, 2010.

[55] R. J. Delfino, N. Staimer, T. Tjoa et al., "Air pollution exposures and circulating biomarkers of effect in a susceptible population: clues to potential causal component mixtures and mechanisms," Environmental Health Perspectives, vol. 117, no. 8, pp. 1232-1238, 2009.

[56] R. J. Delfino, N. Staimer, T. Tjoa et al., "Association of biomarkers of systemic inflammation with organic components and source tracers in quasi-ultrafine particles," Environmental Health Perspectives, vol. 118, no. 6, pp. 756762, 2010.

[57] A. Radomski, P. Jurasz, D. Alonso-Escolano et al., "Nanoparticle-induced platelet aggregation and vascular thrombosis," British Journal of Pharmacology, vol. 146, no. 6, pp. 882-893, 2005.

[58] E. A. Jun, K. M. Lim, K. Kim et al., "Silver nanoparticles enhance thrombus formation through increased platelet aggregation and procoagulant activity," Nanotoxicology, vol. 5, no. 2, pp. 157-167, 2011.

[59] P. Bihari, M. Holzer, M. Praetner et al., "Single-walled carbon nanotubes activate platelets and accelerate thrombus formation in the microcirculation," Toxicology, vol. 269, no. 2-3, pp. 148-154, 2010.

[60] E. Kilinç, H. Schulz, G. J. A. J. M. Kuiper et al., "The procoagulant effects of fine particulate matter in vivo," Particle and Fibre Toxicology, vol. 8, article 12, 2011.

[61] Z. Li, T. Hulderman, R. Salmen et al., "Cardiovascular effects of pulmonary exposure to single-wall carbon nanotubes," Environmental Health Perspectives, vol. 115, no. 3, pp. 377382, 2007.

[62] X. Liu and J. Sun, "Endothelial cells dysfunction induced by silica nanoparticles through oxidative stress via JNK/P53 and NF- $\kappa$ B pathways," Biomaterials, vol. 31 , no. 32, pp. $8198-$ $8209,2010$.

[63] T. R. Nurkiewicz, D. W. Porter, A. F. Hubbs et al., "Nanoparticle inhalation augments particle-dependent systemic microvascular dysfunction," Particle and Fibre Toxicology, vol. 5, article 1, 2008.

[64] L. K. Vesterdal, J. K. Folkmann, N. R. Jacobsen et al., "Pulmonary exposure to carbon black nanoparticles and vascular effects," Particle and Fibre Toxicology, vol. 7, article 33, 2010.

[65] S. Loft, P. H. Danielsen, L. Mikkelsen, L. Risom, L. Forchhammer, and P. Møller, "Biomarkers of oxidative damage to DNA and repair," Biochemical Society Transactions, vol. 36, no. 5, pp. 1071-1076, 2008.

[66] N. L. Mills, K. Donaldson, P. W. Hadoke et al., "Adverse cardiovascular effects of air pollution," Nature Clinical Practice Cardiovascular Medicine, vol. 6, no. 1, pp. 36-44, 2009.
[67] P. Møller and S. Loft, "Oxidative damage to DNA and lipids as biomarkers of exposure to air pollution," Environmental Health Perspectives, vol. 118, no. 8, pp. 1126-1136, 2010.

[68] M. S. Cooke, P. T. Henderson, and M. D. Evans, "Sources of extracellular, oxidatively-modified DNA lesions: implications for their measurement in urine," Journal of Clinical Biochemistry and Nutrition, vol. 45, no. 3, pp. 255-270, 2009.

[69] J. J. Sauvain, A. Setyan, P. Wild et al., "Biomarkers of oxidative stress and its association with the urinary reducing capacity in bus maintenance workers," Journal of Occupational Medicine and Toxicology, vol. 6, no. 1, article 18, 2011.

[70] L. Gonzalez, D. Lison, and M. Kirsch-Volders, "Genotoxicity of engineered nanomaterials: a critical review," Nanotoxicology, vol. 2, no. 4, pp. 252-273, 2008.

[71] N. Singh, B. Manshian, G. J. S. Jenkins et al., "NanoGenotoxicology: the DNA damaging potential of engineered nanomaterials," Biomaterials, vol. 30, no. 23-24, pp. 38913914, 2009.

[72] J. Ponti, E. Sabbioni, B. Munaro et al., "Genotoxicity and morphological transformation induced by cobalt nanoparticles and cobalt chloride: an in vitro study in Balb/3T3 mouse fibroblasts," Mutagenesis, vol. 24, no. 5, pp. 439-445, 2009.

[73] G. C. M. Falck, H. K. Lindberg, S. Suhonen et al., "Genotoxic effects of nanosized and fine $\mathrm{TiO}_{2}$," Human and Experimental Toxicology, vol. 28, no. 6-7, pp. 339-352, 2009.

[74] J. Muller, I. Decordier, P. H. Hoet et al., "Clastogenic and aneugenic effects of multi-wall carbon nanotubes in epithelial cells," Carcinogenesis, vol. 29, no. 2, pp. 427-433, 2008.

[75] L. Migliore, D. Saracino, A. Bonelli et al., "Carbon nanotubes induce oxidative DNA damage in RAW264.7 cells," Environmental and Molecular Mutagenesis, vol. 51, no. 4, pp. 294303, 2010.

[76] H. L. Karlsson, "The comet assay in nanotoxicology research," Analytical and Bioanalytical Chemistry, vol. 398, no. 2, pp. 651-666, 2010.

[77] V. Valinluck, H. H. Tsai, D. K. Rogstad, A. Burdzy, A. Bird, and L. C. Sowers, "Oxidative damage to methyl-CpG sequences inhibits the binding of the methyl-CpG binding domain (MBD) of methyl-CpG binding protein 2 (MeCP2)," Nucleic Acids Research, vol. 32, no. 14, pp. 4100-4108, 2004.

[78] D. Fragou, A. Fragou, S. Kouidou, S. Njau, and L. Kovatsi, "Epigenetic mechanisms in metal toxicity," Toxicology Mechanisms and Methods, vol. 21, no. 4, pp. 343-352, 2011.

[79] L. Tarantini, M. Bonzini, P. Apostoli et al., "Effects of particulate matter on genomic DNA methylation content and iNOS promoter methylation," Environmental Health Perspectives, vol. 117, no. 2, pp. 217-222, 2009.

[80] C. T. Ng, S. T. Dheen, W. C. G. Yip, C. N. Ong, B. H. Bay, and L. Y. Lanry Yung, "The induction of epigenetic regulation of PROS1 gene in lung fibroblasts by gold nanoparticles and implications for potential lung injury," Biomaterials, vol. 32, pp. 7609-7615, 2011.

[81] R. S. H. Yang, L. W. Chang, J. P. Wu et al., "Persistent tissue kinetics and redistribution of nanoparticles, quantum Dot 705, in Mice: ICP-MS quantitative assessment," Environmental Health Perspectives, vol. 115, no. 9, pp. 1339-1343, 2007.

[82] S. T. Yang, W. Guo, Y. Lin et al., "Biodistribution of pristine single-walled carbon nanotubes in vivo," Journal of Physical Chemistry C, vol. 111, no. 48, pp. 17761-17764, 2007.

[83] J. Wang, Y. Liu, F. Jiao et al., "Time-dependent translocation and potential impairment on central nervous system by intranasally instilled $\mathrm{TiO}_{2}$ nanoparticles," Toxicology, vol. 254, no. 1-2, pp. 82-90, 2008. 
[84] A. Elder, R. Gelein, V. Silva et al., "Translocation of inhaled ultrafine manganese oxide particles to the central nervous system," Environmental Health Perspectives, vol. 114, no. 8, pp. 1172-1178, 2006.

[85] B. Wang, W. Feng, M. Zhu et al., "Neurotoxicity of low-dose repeatedly intranasal instillation of nano- and submicronsized ferric oxide particles in mice," Journal of Nanoparticle Research, vol. 11, no. 1, pp. 41-53, 2009.

[86] S. Tin-Tin-Win, S. Yamamoto, S. Ahmed, M. Kakeyama, T. Kobayashi, and H. Fujimaki, "Brain cytokine and chemokine mRNA expression in mice induced by intranasal instillation with ultrafine carbon black," Toxicology Letters, vol. 163, no. 2, pp. 153-160, 2006.

[87] Y. L. Hu and J. Q. Gao, "Potential neurotoxicity of nanoparticles," International Journal of Pharmaceutics, vol. 394, no. 1-2, pp. 115-121, 2010.

[88] Z. Wang, J. Zhao, F. Li, D. Gao, and B. Xing, "Adsorption and inhibition of acetylcholinesterase by different nanoparticles," Chemosphere, vol. 77, no. 1, pp. 67-73, 2009.

[89] J. Wang, M. F. Rahman, H. M. Duhart et al., "Expression changes of dopaminergic system-related genes in PC12 cells induced by manganese, silver, or copper nanoparticles," NeuroToxicology, vol. 30, no. 6, pp. 926-933, 2009.

[90] J. Wu, C. Wang, J. Sun, and Y. Xue, "Neurotoxicity of silica nanoparticles: brain localization and dopaminergic neurons damage pathways," ACS Nano, vol. 5, no. 6, pp. 4476-4489, 2011.

[91] K. Sriram, G. X. Lin, A. M. Jefferson et al., "Dopaminergic neurotoxicity following pulmonary exposure to manganesecontaining welding fumes," Archives of Toxicology, vol. 84, no. 7, pp. 521-540, 2010.

[92] L. Manzo, F. Artigas, E. Martínez et al., "Biochemical markers of neurotoxicity. A review of mechanistic studies and applications," Human and Experimental Toxicology, vol. 15, supplement 1, pp. S20-S35, 1996.

[93] A. Mutti, E. Bergamaschi, R. Alinovi, R. Lucchini, M. V. Vettori, and I. Franchini, "Serum prolactin in subjects occupationally exposed to manganese," Annals of Clinical and Laboratory Science, vol. 26, no. 1, pp. 10-17, 1996.

[94] M. Simkó and M. O. Mattsson, "Risks from accidental exposures to engineered nanoparticles and neurological health effects: a critical review," Particle and Fibre Toxicology, vol. 7, article 42, 2010.

[95] K. Hildebrandt, R. Rücker, W. Koenig et al., "Short-term effects of air pollution: a panel study of blood markers in patients with chronic pulmonary disease," Particle and Fibre Toxicology, vol. 6, pp. 25-40, 2009.

[96] M. Nasterlack, A. Zober, and C. Oberlinner, "Considerations on occupational medical surveillance in employees handling nanoparticles," International Archives of Occupational and Environmental Health, vol. 81, no. 6, pp. 721-726, 2008.

[97] P. A. Schulte, D. Trout, R. D. Zumwalde et al., "Options for occupational health surveillance of workers potentially exposed to engineered nanoparticles: state of the science," Journal of Occupational and Environmental Medicine, vol. 50, no. 5, pp. 517-526, 2008.

[98] P. A. Schulte, M. K. Schubauer-Berigan, C. Mayweather, C. L. Geraci, R. Zumwalde, and J. L. McKernan, "Issues in the development of epidemiologic studies of workers exposed to engineered nanoparticles," Journal of Occupational and Environmental Medicine, vol. 51, no. 3, pp. 323-335, 2009.

[99] N. Li and A. E. Nel, "Feasibility of biomarker studies for engineered nanoparticles: what can be learned from air pollution research," Journal of Occupational and Environmental Medicine, vol. 53, no. 6, pp. S74-S79, 2011.

[100] E. Bergamaschi, G. De Palma, P. Mozzoni et al., "Polymorphism of Quinone-metabolizing enzymes and susceptibility to ozone-reduced acute effects," American Journal of Respiratory and Critical Care Medicine, vol. 163, no. 6, pp. 14261431,2001

[101] F. Alessandrini, I. Weichenmeier, E. van Miert et al., "Effects of ultrafine particles-induced oxidative stress on Clara cells in allergic lung inflammation," Particle and Fibre Toxicology, vol. 7, article 11, 2010.

[102] S. H. Liou, M.H. Lin, C. H. Hsu et al., "Pilot study of health hazards among engineered nanoparticles manufacturing workers," Journal of Occupational and Environonmental Medicine, vol. 60, supplement 1, article A100, 2010.

[103] M. Goldoni, A. Caglieri, G. De Palma et al., "Development and set-up of a portable device to monitor airway exhalation and deposition of particulate matter," Biomarkers, vol. 14, no. 5, pp. 326-339, 2009.

[104] M. Goldoni, O. Acampa, S. Longo et al., "Inter- and intrasubject variability of kinetics of airway exhalation and deposition of particulate matter in indoor polluted environments," International Journal of Hygiene and Environmental Health, vol. 215, pp. 312-319, 2012.

[105] M. Goldoni, S. Catalani, G. De Palma et al., "Exhaled breath condensate as a suitable matrix to assess lung dose and effects in workers exposed to cobalt and tungsten," Environmental Health Perspectives, vol. 112, no. 13, pp. 1293-1298, 2004.

[106] M. Goldoni, A. Caglieri, D. Poli et al., "Determination of hexavalent chromium in exhaled breath condensate and environmental air among chrome plating workers," Analytica Chimica Acta, vol. 562, no. 2, pp. 229-235, 2006.

[107] E. Bergamaschi, "Occupational exposure to nanomaterials: present knowledge and future development," Nanotoxicology, vol. 3, no. 3, pp. 194-201, 2009.

[108] P. A. Schulte and D. B. Trout, "Nanomaterials and worker health: medical surveillance, exposure registries, and epidemiologic research," Journal of Occupational and Environmental Medicine, vol. 53, no. 6, pp. S3-S7, 2011.

[109] M. K. Schubauer-Berigan, M. M. Dahm, and M. S. Yencken, "Engineered carbonaceous nanomaterials manufacturers in the United States: workforce size, characteristics, and feasibility of epidemiologic studies," Journal of Occupational and Environmental Medicine, vol. 53, no. 6, pp. S62-S67, 2011.

[110] O. Boutou-Kempf, J. L. Marchand, A. Radauceanu et al., "Development of a French epidemiological surveillance system of workers producing or handling engineered nanomaterials in the workplace," Journal of Occupational and Environmental Medicine, vol. 53, no. 6, pp. S103-S107, 2011. 

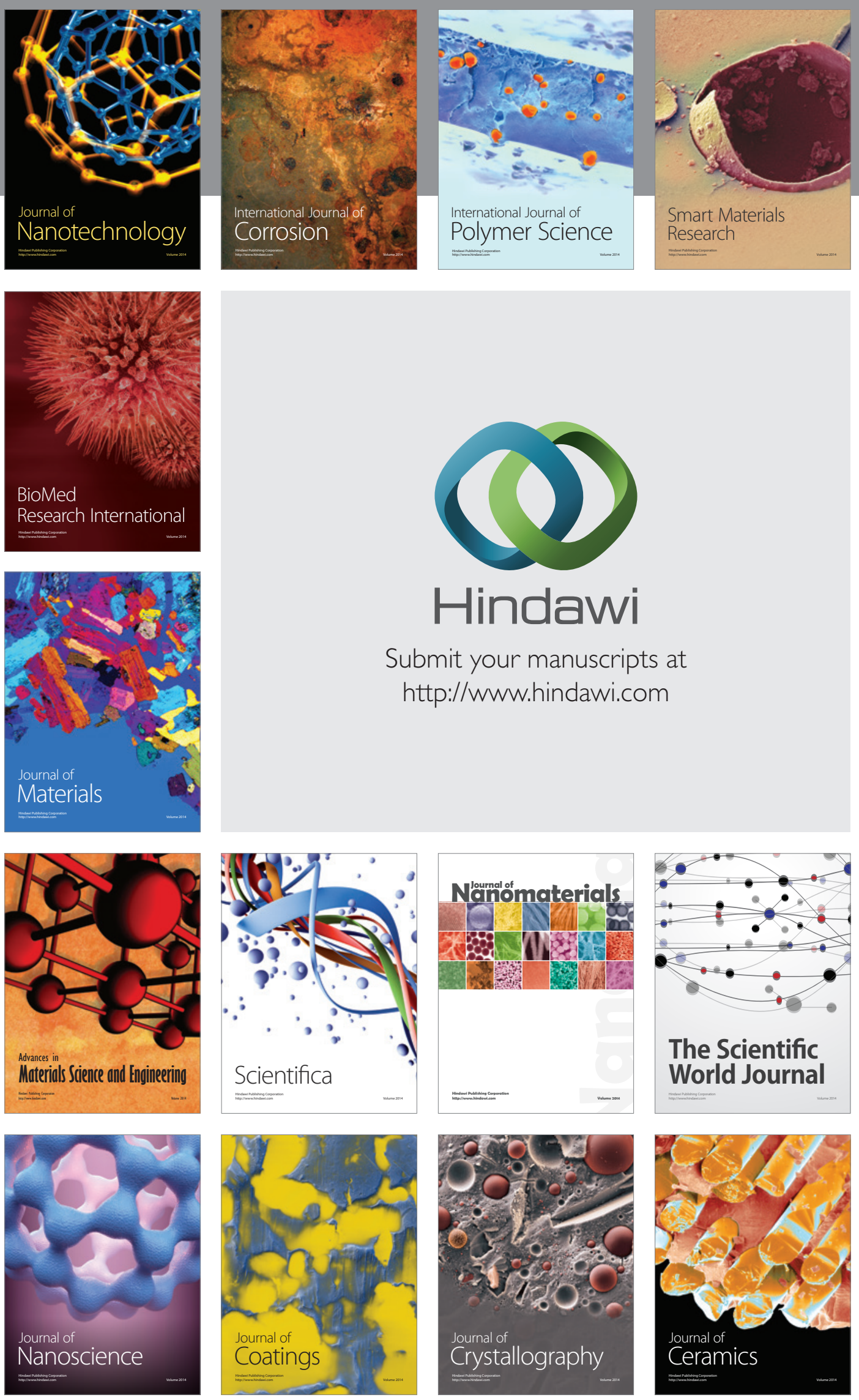

The Scientific World Journal

Submit your manuscripts at

http://www.hindawi.com

\section{World Journal}

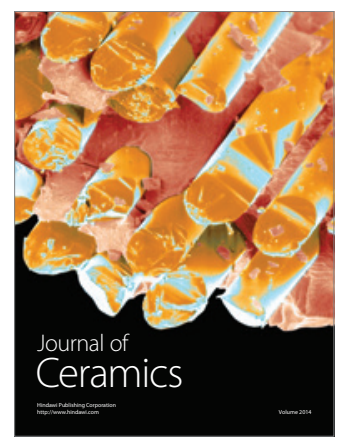

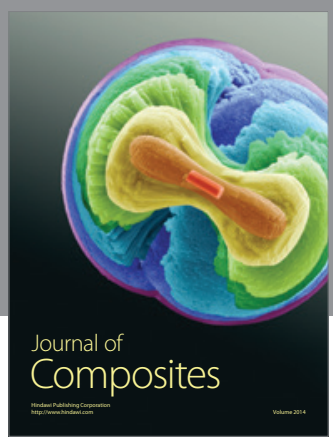
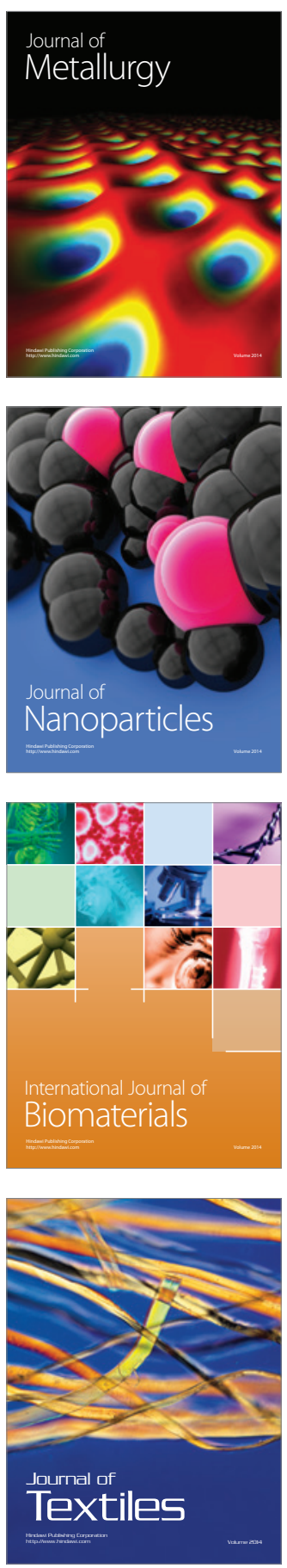